\title{
A Comparison of the Effects of Balance Training and Technological Games on Balance in Hearing-Impaired Individuals
}

\author{
Mustafa Kaya ${ }^{1}$, Nazmi Sarıtaş ${ }^{1}$ \\ ${ }^{1}$ Erciyes University, Faculty of Sport Sciences, Kayseri, Turkey \\ Correspondence: Mustafa Kaya, Erciyes University, Sport Sciences Faculty, Physical Education and Sport Department, \\ Campus 38039, Kayseri, Turkey.
}

Received: January 30, 2019

Accepted: February 10, 2019

Online Published: February 13, 2019

doi:10.11114/jets.v7i3S.4055

URL: https://doi.org/10.11114/jets.v7i3S.4055

\begin{abstract}
It is aimed to compare the effects of the two different methods as balance training and wii fit balance games based on game technology on the balance functions of hearing-impaired individuals.

36 male born deaf individuals between the ages of 18-22 and playing sports actively have participated in the study. The first group consisted of the ones having balance training, the second group consisted of those playing technological games, and the third group (control group) consisted of individuals having no balance training. The first group was given balance training 3 days a week for 8 weeks. The second group was made to play 30-minute wii fit three days a week for 8 weeks.

Statistical difference was between the group playing technological games and control group, and between the group having balance training and control group $(\mathrm{p}<0.01)$.

A statistical difference was found in dynamic balance values after the study. In the after values, a statistical difference occurred between the control group and the group having balance training and the group playing technological games $(\mathrm{p}<0.05)$.

In dynamic balance values, a statistical difference occurred in before and after values of the group having balance training and the group playing technological games $(\mathrm{p}<0.01)$.

As a result of the study comparing the effects of the balance training and game technology based wii fit methods on hearing impaired individuals, it is considered that both practices will be efficient for hearing impaired individuals to improve movements and balance values and to increase daily life activities.
\end{abstract}

Keywords: hearing impaired, progressive balance training, wii fit

\section{Introduction}

The young tend to be less active physically since they are more interested in the technology and information as a result of the improvements in these areas (Vernadakis et al., 2012). Since technological video games are motivating for children and children like them much more, it has become a case to be considered to be used in education (Bayırtepe \& Tüzün, 2007). There are studies in the literature examining that Nintendo Wii fit, which is a technological game used in the study, improve balance and health (Demir \& Akın, 2018). Nintendo Wii (N-Wii) is one of the methods that are frequently used for virtual reality applications, and information on different effects on those having neurologic activations exists in the literature (Saposnik et al., 2010; Piron et al., 2009). Wii is a game console developed by Nintendo company and released in 2006 (Liuzzo et al., 2015; Çekok \& Tarsuslu Şimşek, 2016). Nintendo Wii Fit is a popular balance training tool due to its accessibility and low cost (Cone, Levy \& Goble, 2015). It is used in rehabilitation because of its characteristics of the adaptation to weight-bearing and postural change, improving motor skills by using visual-cognitive systems, giving feedback about the performance, individualization according to the needs, displaying the changes of direction, speed and acceleration, being interactive, being motivating, being easily accessible, being portable and being applied (Bateni, 2011; Deutsch et al., 2008). The device can perceive simple motions with its motion-sensitive sensors. For instance, extremity movements or location change can be detected by using mouse or Wii remote control (Shih, 2011). Exercises done with N-Wii systems are not dangerous, and they have characteristics such as being customized, being consisted of target-specific activities and giving feedback during the application easily. In virtual reality approaches such as N-Wii, concepts playing role in motor learning are emphasized. 
These systems are preferred since they involve plenty of goal-oriented repetitions, provide visual, auditory and sensory feedback, and motivate the users due to their entertaining activities (Todorov, Shadmer \& Bizzi, 1997).

Balance can be defined as the adaptation of the body to the gravity in motion and stationary state (Leavey, Sandrey \& Dahmer, 2010). Balance is the ability of an object or a person to stand without falling (Hazar \& Taşmektepligil, 2008). Balance is the ability of the body to provide the expected position in static and dynamic movements (Kaya \& Pulur, 2003). Three main sensory systems are used for balance and postural stability. Visual system is the first system in which the movements are planned. Vestibular system is a structure perceiving rectilinear and angular motions, and proprioceptive system consists of sensors sensitive for gravity direction and body segments' positions, speed and their contact with objects (Winter, 1995).

Static balance tests are performed by maintaining the stability of the body without changing the supporting surface and recording the time of maintaining different positions (Arslan, 2009). Dynamic balance is defined as the ability to maintain the equilibrium of the body while in motion (Kaya \& Pulur, 2003). Balance is important to perform the motions in sports.

In this study, it was aimed to investigate the effects of the two different methods as balance training and game technology based Wii fit game on the balance functions of hearing-impaired individuals playing sports.

\section{Method}

\subsection{Research Model}

\section{Balance Measurement Methods}

In the study, biodex balance system (Biodex, Inc, Shirley, New York) was used for balance measurement.

Biodex balance system uses a round platform that can be moved at anterior-posterior and medial lateral axis synchronously. It gives three result values as overall stability index, anterior-posterior stability index and medial-lateral stability index (Cachupe et al., 2001). Among the obtained balance indices, overall balance index is accepted as the best indicator for overall ability (OA). In our study, the subjects stood on both feet while their eyes are open and with a gap in the shoulder width between the feet, and the static balance and the 4th level dynamic balance tests were used. Tests were performed in straight position with two feet.

Balance tests were performed as 1 repetition for $1 \mathrm{~min}$. Before the tests, each volunteer performed a trial for $10 \mathrm{sec}$ in order to accommodate the static and dynamic balance tests and to get to know them. The participants were asked not to move and speak during the test. The tests of the participants losing their balance were started over again.

\subsection{Research Group}

36 male born deaf individuals between the ages of 18-22 and playing sports actively have participated in the study. The participants were divided into three groups randomly. The first group $(n=12)$ consisted of the ones having balance training, the second group $(\mathrm{n}=12)$ consisted of those playing technological games, and the third group (control group) $(\mathrm{n}=12)$ consisted of individuals having no balance training. The first group was given balance training 3 days a week for 8 weeks. The second group was made to play 30-minute wii fit three days a week for 8 weeks. The third group that was the control group wasn't given any balance training.

\subsection{Data Collection Tools}

\section{Progressive Balance Training Performance:}

1. Head rotation and flexion: In this exercise, it is aimed to keep the balance during the head's rotation to the left, right and up. The experimental group was asked to do more head rotation and flexion depending on their level, increase the speed of the movement and do successive movements in order to make the exercise more difficult.

2. Body Rotation: It is expected to keep the balance during the body's rotation to the right, left and back. In order to make the exercise difficult, the volunteers were asked to increase the body rotation depending on their level, increase the speed of the movement, do successive movements and extend to an object during the body rotation.

3. Standing by one leg support: It is expected to keep the balance while one foot is on the step. In order to make the exercise difficult, the volunteers were asked to increase the height of the step depending on their level and to extend to an object while one foot is on the step.

4. Standing on one leg: The volunteer is asked to keep the balance by lifting one leg from the ground. In order to make the exercise difficult, the time of standing on one leg was increased and head movements were added.

\section{Game Practice with Technological Games:}

1. Balance bubble: In this game, the participants represent the person in the bubble. In order to avoid hitting the edges of the stream they are moving along in the bubble, they need to transfer weight to the right and left. At the beginning of 
the game, the targets of the game are stated in writing, and the participants are asked to move their character along the stream by bending to the right, left, front and back in order to move along, and the instructions are also indicated visually with an animation. The participants need to give weight forward to move forward, and as the amount of the weight given forward increases, the character in the game move faster on the stream, the game is completed in a shorter time and a higher score is obtained. Hitting stream edges or exploding the bubble by the bees around causes the game to end. The participants have $90 \mathrm{sec}$. for the game. Each participant played balance bubble game and they were given 5 min. to have a rest.

2. Ski slalom: In this game, volunteers represent the person doing ski slalom. When descending from the top of the ski track, they need to pass through the target rangeindicated by the two flags by transferring weight to the right or left. At the beginning of the game, the participants are given written instructions of that "go down the ski track by bending to the right and left/try to pass through the gap between the flags by bending to the right and left," and they are also indicated visually by an animation. The movements of the gravity center of the participants are shown on a graph. They need to transfer weight to the front to move forward, and as the weight transferred to the front increases, the character in the game moves faster, and the obtained score will be higher. Hitting the target points or not being able to pass through the target gap cause the players to lose point, each faulty passing is multiplied with the penalty point of 7 seconds, and total score is obtained by adding it to the time of completing the whole track. Each volunteer played the ski slalom game and they were given 5 minutes to have a rest.

\subsection{Statistical Analysis of Data}

IBM-SPSS 22.0 program was used for the statistical analysis of the data. Shapiro-Wilk test was performed for the normality test of the data. The data were seen distributed normally. Statistical notation was indicated by arithmetic mean and standard deviation. Within-group comparisons were performed by paired sample $t$ test. One way anova test was used to compare the between-groups measurements. Tukey test of post hoc tests was used to determine the between-groups difference. Significance level was taken as $\mathrm{p}<0.05$.

\section{Results}

Table 1.The physical characteristics of the groups

\begin{tabular}{|c|c|c|c|c|c|}
\hline \multirow{2}{*}{ Variable } & \multicolumn{2}{|r|}{ Before } & After & \multirow[b]{2}{*}{$\mathbf{t}$} & \multirow[b]{2}{*}{ p } \\
\hline & Group & $\overline{\mathbf{X}} \pm \mathbf{S D}$ & $\overline{\mathbf{X}} \pm \mathbf{S D}$ & & \\
\hline \multirow{3}{*}{ Age (years) } & $1(n=12)$ & $20.17 \pm 1.47$ & $20.17 \pm 1.47$ & & \\
\hline & $2(\mathrm{n}=12)$ & $20.08 \pm 1.24$ & $20.08 \pm 1.24$ & & \\
\hline & $3(n=12)$ & $20.17 \pm 1.47$ & $20.17 \pm 1.47$ & & \\
\hline \multirow{3}{*}{ Height (cm) } & $1(\mathrm{n}=12)$ & $172.08 \pm 2.23$ & $172.08 \pm 2.23$ & & \\
\hline & $2(n=12)$ & $173.50 \pm 3.00$ & $173.50 \pm 3.00$ & & \\
\hline & $3(\mathrm{n}=12)$ & $172.25 \pm 1.82$ & $172.25 \pm 1.82$ & & \\
\hline \multirow{3}{*}{ Body weight $(\mathrm{kg})$} & $1(\mathrm{n}=12)$ & $63.67 \pm 2.96$ & $63.42 \pm 2.75$ & 1.000 & 0.339 \\
\hline & $2(\mathrm{n}=12)$ & $63.42 \pm 3.50$ & $63.17 \pm 3.46$ & 1.000 & 0.339 \\
\hline & $3(n=12)$ & $65.00 \pm 3.05$ & $65.33 \pm 2.99$ & -1.483 & 0.166 \\
\hline \multirow{3}{*}{ BMI $\left(\mathrm{kg} / \mathrm{m}^{2}\right)$} & $1(\mathrm{n}=12)$ & $21.51 \pm 1.14$ & $21.43 \pm 1.10$ & 0.975 & 0.351 \\
\hline & $2(n=12)$ & $21.07 \pm 1.04$ & $20.98 \pm 0.98$ & 1.017 & 0.331 \\
\hline & $3(\mathrm{n}=12)$ & $21.91 \pm 1.05$ & $22.02 \pm 1.06$ & -1.495 & 0.163 \\
\hline
\end{tabular}

Before and after the study, no statistical difference was observed in the age and stature $(\mathrm{F}=0.014 ; \mathrm{p}=0.986),(\mathrm{F}=1.248$; $0.300)$ values of the groups. Within-groups and between-groups, no statistical difference occurred in body weight before $(\mathrm{F}=0.860 ; \mathrm{p}=0.432)$ and after $(\mathrm{F}=1.776 ; \mathrm{p}=0.185)$, and body mass indices before $(\mathrm{F}=1.836 ; \mathrm{p}=0.175)$ and after $(\mathrm{F}=2.985$; $\mathrm{p}=0.064)(\mathrm{p}>0.05)$.

Table 2. The comparison of the static and dynamic balance values of the group having progressive balance training and the group playing technological game with the control group

\begin{tabular}{lccccc}
\hline Variable & & Before & After & & \\
& Group & $\overline{\mathbf{X}} \pm$ SD & t & p \\
\hline \multirow{3}{*}{ Static Balance } & $1(\mathrm{n}=12)$ & $0.68 \pm 0.18$ & $0.60 \pm 0.13^{\mathrm{a}}$ & 2.017 & 0.069 \\
& $2(\mathrm{n}=12)$ & $0.79 \pm 0.17$ & $0.67 \pm 0.11^{\mathrm{a}}$ & $\mathbf{3 . 8 0 4}$ & $\mathbf{0 . 0 0 3}^{* *}$ \\
& $3(\mathrm{n}=12)$ & $0.82 \pm 0.10$ & $0.81 \pm 0.07^{\mathrm{b}}$ & 0.248 & 0.809 \\
\hline \multirow{3}{*}{ Dynamic Balance } & $1(\mathrm{n}=12)$ & $1.65 \pm 0.26$ & $1.46 \pm 0.22^{\mathrm{a}}$ & $\mathbf{3 . 7 2 7}$ & $\mathbf{0 . 0 0 3}^{* *}$ \\
& $2(\mathrm{n}=12)$ & $1.78 \pm 0.36$ & $1.48 \pm 0.17^{\mathrm{a}}$ & $\mathbf{3 . 7 1 7}$ & $\mathbf{0 . 0 0 3}^{* *}$ \\
& $3(\mathrm{n}=12)$ & $1.87 \pm 0.28$ & $1.78 \pm 0.23^{\mathrm{b}}$ & 1.116 & 0.288 \\
\hline
\end{tabular}

ab: there is no difference between the groups having the same letter in the same column. There is a difference between the groups having different letters. 
No statistical difference was observed in the static $(\mathrm{F}=2.872 ; \mathrm{p}=0.071)$ and dynamic balance $(\mathrm{F}=1.562 ; \mathrm{p}=0.225)$ values of the groups before the study ( $>0.05$ ).

A statistical difference was observed in the static balance $(\mathrm{F}=12.597 ; \mathrm{p}=0.001)$ values of the groups after the study. This difference was between the group playing technological games and control group, and the group having balance training and the control group $(\mathrm{p}<0.05)$. No statistical difference was found between the group having progressive balance training and the group playing technological games ( $p>0.05)$. In addition, a statistical difference occurred in before and after values of the statistic balance of the group playing technological games $(\mathrm{p}<0.01)$, but no statistical difference was observed in before and after values of the group having balance training and the control group ( $p>0.05)$.

A statistical difference was found in dynamic balance values after the study ( $\mathrm{F}=9.418 ; \mathrm{p}=0.001)$. After the study, a statistical difference occurred between the group playing technological games and the control group, and between the group having balance training and the control group $(\mathrm{p}<0.05)$, but no difference was observed between the group playing technological games and the group having balance training $(\mathrm{p}>0.05)$.

Before and after the study, a statistical difference occurred in dynamic balance values of the group having balance training and the group playing technological games $(\mathrm{p}<0.01)$. No difference was observed in the before and after values of the control group ( $p>0.05)$.

\section{Discussion and Conclusion}

There are studies in the literature in which Wii Fit was used in balance training for elderly people (Pigford \& Andrews, 2010), cerebral palsy (Deutsch et al., 2008), Parkinson disease (Esculier et al., 2012) and multiple sclerosis (MS) (Plow \& Finlayson, 2011). However, no reference was detected in which Wii Fit was used to provide balance improvement in hearing impaired individuals playing sport.

In this study, it was aimed to compare the effects of the two different methods as balance training and game technology based Wii Fit game on the balance functions of hearing impaired individuals.

A significant difference occurred when the static and dynamic balance values of the hearing impaired individuals having balance training and those playing technological games are compared with the control group's, but no statistical difference was observed between the group having balance training and the group playing technological games.

There is a study stating that progressive balance training contribute balance to improve (Granacher, Gollhofer \& Kriemler, 2010). In addition, the study reporting Wii Fit balance training is efficient in both healthy individuals and the ones in the clinic to improve balance exists in the literature (Goble, Cone \& Fling, 2014).

In a research, children playing video games actively were divided into groups. The first group played active video games that improves postural stability, the second group did agility, balance and coordination exercises, and the third group did ordinary physical education activities. The performances lasted for 34 minutes a day, for 4 days a week for 6 weeks. As a result of the performances, the active video game group and the group of agility, balance and coordination made progress almost evenly. However it was found that the control group did not make any progress (Sheehan \& Katz, 2013). Similarly, in the study that was aimed to examine the balance characteristic of the students studying at the department of physical education teaching, the effect of balance trainings and active video games on balance was compared. 32 randomly selected students participated in the study voluntarily. The students were divided into two groups. The first group had balance trainings and the second played active video games. Both training programs lasted for 24 minutes a day, twice a week for 8 weeks, and as a result of the study it was observed that both methods improved balance (Vernadakis et al., 2012). In a study conducted on the balance improvement of 40 young healthy participants between the ages of 18-35, two groups were formed as Wii fit balance group and control group. The Wii fit group played 7 Wii Fit games for 35 minutes as total 3-4 hours a week for 6 weeks, and the balance group was stated to make a better progress. These results indicate that balance games contribute to process plenty of sensory information and are more useful (Cone, Levy \& Goble, 2015). Another study was conducted to compare the efficiency of balance trainings and video game based balance programs in improving balance performance. Pretest and posttest was performed in the study in which star excursion balance test. The participants had balance exercises and played Nintendo Wii Fit or Dance Dance Revolution game 3 days a week for 4 weeks. As a result of the study, the group playing video games was observed to make better progress than the balance group (Brumels et al., 2008). In the study, when the balance values of the individuals having balance training and those playing technological games are examined, it is observed that these values are close to each other, and the values of the individuals having balance training are better numerically and it is considered that this is the result of their more active lifestyle. According to the result of the study by Brumels et al., (2008), technological games can be stated to improve balance values. Indeed, it is seen that the improvement in the balance values of the group playing technological games in our study is supported by this study. The knowledge in the literature is similar to our study.

The most important problem of the born deaf individuals is the functional inefficacy of the balance centers that work 
correlatively with each other since they cannot perceive the stimulus from outside aurally. Therefore, static and dynamic balances are adversely affected due to the lack of vestibular system functions even if visual perceptions, proprioceptors and antigravity muscles function properly (Kurt, 2007). Although all the participants were born deaf individuals in this study, significant results were obtained when balance training group is compared with the control group, and these results revealed that born deaf individuals could obtain positive results by balance trainings. In addition, it is recommended that new studies comparing born deaf individuals and late-deafened individuals should be conducted to contribute the literature.

In a study conducted on the effects of the exercise activities in hearing-impaired children, it is stated that exercises affect visual motoric characteristics and they are efficient to correct the deficiencies related to vestibular system (Rajendran, Roy \& Jeevanantham). Sports activities, learning and exercises that are performed for a long time period improve the efficiency of dynamic and static postural control in daily life activities (Perrin et al., 2002). In the light of this information it is recommended hearing-impaired individuals to do balance training and to play technological games improving balance as well as doing sports activities.

Consequently, this study, which is the first study in the literature that compared the effects of balance training and game technology based Wii Fit game methods in hearing-impaired individuals, reveals that both methods are efficient in improving movements, balance functions, confidence feeling during the activity and increasing daily life activities in hearing-impaired individuals. When the two methods are compared, both are thought to be efficient on the improvement of balance elements.

\section{References}

Arslan, F. (2009). The effect of 8 week proprioception training program on dynamic postural control in Taekwondo athletes.PhD Thesis, Gazi University, Institute of Health Sciences, Department of Physical Training and Sports, Ankara. [Turkish].

Bateni, H. (2011). Changes in balance in older adults based on use of physical therapy vs. the Wii Fit gaming system: a preliminary study. Physiotherapy, 98(3), 211-216. https://doi.org/10.1016/j.physio.2011.02.004

Bayırtepe, E., \& Tüzün, H. (2007). The effect of the game based learning environment on students' success in computer class and their perception of self-efficacy. Hacettepe University Faculty of Education Journal, 33(33), 41-54. https://doi.org/10.24106/kefdergi.2074

Brumels, K. A., Blasius, T., Cortright, T., Oumedian, D., \& Solberg, B. (2008). Comparison of efficacy between traditional and video game based balance programs. Clinical Kinesiology: Journal of the American Kinesiotherapy Association, 62(4), 26-32.

Cachupe, W. J., Shifflett, B., Kahanov, L., \& Wughalter, E. H. (2001). Reliability of biodex balance system measures. Measurement in Physical Education and Exercise Science, 5(2), 97-108. https://doi.org/10.1207/S15327841MPEE0502_3

Çekok, K., \& Tarsuslu, Ş. T. (2016). Effect of nintendo wii games on balance and upper extremity functions in stroke patients, Turk J Physiother Rehabil, 27(2), 61-71. [Turkish].

Cone, B. L., Levy, S. S., \& Goble, D. J. (2015). Wii Fit exer-game training improves sensory weighting and dynamic balance in healthy young adults. Gait \& posture, 41(2), 711-715. https://doi.org/10.1016/j.gaitpost.2015.01.030

Demir, A., \& Akın, M. (2018). Examining the effects of active video games and balance training on static balance in 6 years old children, Journal of Human Sciences, 15(4), 2376-2386. https://doi.org/10.14687/jhs.v15i4.5435

Deutsch, J. E., Borbely, M., Filler, J., Huhn, K., \& Guarrera-Bowlby, P. (2008). Use of a low-cost, commercially available gaming console (wii) for rehabilitation of an adolescent with cerebral palsy. Phys Ther, 88(10), 1196-1207. https://doi.org/10.2522/ptj.20080062

Esculier, J. F., Vaudrin, J., Beriault, P., Gagnon, K., \& Tremblay, L. E. (2012). Home based balance training programme using Wii Fit with balance board for Parkinson's disease: A pilot study. J Rehabil Med, 44(2), 144-150. https://doi.org/10.2340/16501977-0922

Goble, D. J., Cone, B. L., \& Fling, B. W. (2014). Using the Wii Fit as a tool for balance assessment and neurorehabilitation: the first half decade of "Wii-search". Journal of neuroengineering and rehabilitation, 11(1), 12. https://doi.org/10.1186/1743-0003-11-12

Granacher, U., Gollhofer, A., \& Kriemler, S. (2010). Effects of balance training on postural sway, leg extensor strength, and jumping height in adolescents. Research quarterly for exercise and sport, 81(3), 245-251. ISSN: 0270-1367. https://doi.org/10.1080/02701367.2010.10599672 
Hazar, F., \& Taşmektepligil, Y. (2008). Examining the effect of balance and flexibility on agility in pre-pubertal period. Journal of Physical Education and Sports Sciences, 6(1), 9-12. [Turkish].

Kaya, M., \& Pulur, A. (2003). Comparison of static and dynamic balance activities of visually impaired people between the ages of 13-15. Master thesis, Gazi University, Institute of Health Sciences, Department of Physical Training and Sports, Ankara. [Turkish].

Kurt, A. (2007). The effect of regular exercise on balance parameters in hearing impaired and normal individuals, Master thesis, Erciyes University, Institute of Health Sciences, Department of Physical Training and Sports Sciences, Kayseri. [Turkish].

Leavey, V., Sandrey, M. A., \& Dahmer, G. (2010). Comparative effects of a six-week balance, gluteus medius strength, and combined programs on dynamic postural control. Journal of Sport Rehabilitation. 19(3), 268-287. PMID: 20811077. https://doi.org/10.1123/jsr.19.3.268

Liuzzo, D. M., Peters, D. M., Middleton, A., Lanier, W., Chain, R., Barksdale, B., \& Fritz, S. L. (2015). Measurements of weight bearing asymmetry using the nintendo wii fit balance board are not reliable for older adults and individuals with stroke. J. Geriatr Phys Ther., 40(1), 37-41. https://doi.org/10.1519/JPT.0000000000000065

Perrin, P., Deviterne, D., Hugel, F., \& Perrot, C. (2002). Judo, better than dance, develops sensorimotor adaptabilities involved in balance control. Gait Posture, 15(2), 187-194. https://doi.org/10.1016/S0966-6362(01)00149-7

Pigford, T., \& Andrews, A. (2010). Feasibility and benefit of using the Nintendo Wii Fit for balance rehabilitation in an elderly patient experiencing recurrent falls. Journal of Student Physical Therapy Research, 2(1), 12-20.

Piron, L., Turolla, A., Agostini, M., Zucconi, C., Cortese, F., Zampolini, M., ... Tonin, P. (2009). Exercises for paretic upper limb after stroke: a combined virtual-reality and telemedicine approach. Journal Rehabil Med. 2009; 41(12), 1016-20. https://doi.org/10.2340/16501977-0459

Plow, M., \& Finlayson, M. (2011). Potential benefits of nintendo wii fit among people with multiple sclerosis: a longitudinal pilot study. Int. J. MS. Care, 13(1), 21-30. https://doi.org/10.7224/1537-2073-13.1.21

Rajendran, V., Roy, F. G., \& Jeevanantham, D. (2013). Effect of exercise intervention on vestibular related impairments in hearing-impaired children. Alexandria Journal of Medicine, 49(1), 7-12. https://doi.org/10.1016/j.ajme.2012.10.001

Saposnik, G., Mamdani, M., Bayley, M., Thrope, K. E., Hall, Cohen, L. G., \& Teasell, R. (2010). Effectiveness of virtual reality using wii gaming technology in stroke rehabilitation. Stroke, 41(7), 1477-1484. https://doi.org/10.1161/STROKEAHA.110.584979

Sheehan, D. P., \& Katz, L. (2013). The effects of a daily, 6-week exergaming curriculum on balance in fourth grade children. Journal of Sport and Health Science, 2(3), 131-137. https://doi.org/10.1016/j.jshs.2013.02.002

Shih, C. H. (2011).A standing location detector enabling people with developmental disabilities to control environmental stimulation through simple physical activities with Nintendo Wii Balance Boards. Res Dev Disabil. 32(2), 699-704. https://doi.org/10.1016/j.ridd.2010.11.011

Todorov, E., Shadmer, R., \& Bizzi, E. (1997). Augmented feedback presented in a virtual environment accelerates learning of a difficult motor task. J Motor Behav., 29(2), 147-158. https://doi.org/10.1080/00222899709600829

Vernadakis, N., Gioftsidou, A., Antoniou, P., Ioannidis, D., \& Giannousi, M. (2012). The impact of Nintendo Wii to physical education students' balance compared to the traditional approaches. Computers \& Education, 59(2), 196-205. https://doi.org/10.1016/j.compedu.2012.01.003

Winter, D. A. (1995). Human balance and postural control during standing and walking. Gait Posture, 3(4), 193-214. 0966-6362195. https://doi.org/10.1016/0966-6362(96)82849-9

\section{Copyrights}

Copyright for this article is retained by the author(s), with first publication rights granted to the journal.

This is an open-access article distributed under the terms and conditions of the Creative Commons Attribution license which permits unrestricted use, distribution, and reproduction in any medium, provided the original work is properly cited. 